Article

\title{
Eco-Friendly Acaricidal Effects of Nylon 66 Nanofibers via Grafted Clove Bud Oil-Loaded Capsules on House Dust Mites
}

\author{
Joo Ran Kim (1) and Seong Hun Kim * \\ Organic and Nano Engineering; College of Engineering, Hanyang University, Sung-dong-gu, Seoul 04763 , \\ Korea; jk992@cornell.edu \\ * Correspondence: kimsh@hanyang.ac.kr; Tel.: +82-10-3715-0496; Fax: +82-2-2281-2737 \\ Academic Editor: Ana María Díez-Pascual \\ Received: 23 June 2017; Accepted: 6 July 2017; Published: 10 July 2017
}

\begin{abstract}
Acaricidal nylon 66 fabrics (AN66Fs) grafted with clove oil-loaded microcapsules (COMCs) were developed against Dermatophagoides farina (D. gallinae). The average diameter was about $2.9 \mu \mathrm{m}$ with a range of $100 \mathrm{~nm}-8.5 \mu \mathrm{m}$. COMCs carried clove oil loading of about $65 \mathrm{vol} \%$. COMCs were chemically grafted to electrospun nylon nanofibers by the chemical reactions between -OH groups of COMCs and $-\mathrm{COOH}$ end groups of nylon fabrics to form ester linkages. AN66Fs had an effect on $D$. farinae depending on COMCs loadings. The increase in COMCs loading of AN66Fs from 5 to $15 \mathrm{wt} \%$ increased from $22 \%$ to $93 \%$ mortality against D. farinae within $72 \mathrm{~h}$. However, AN66Fs containing over $20 \mathrm{wt} \%$ COMCs were more effective, showing up to $100 \%$ mortality within $24 \mathrm{~h}$ because the large amount of monoterpene alcohol, eugenol. This research suggests the use of clove oil and its major constituent eugenol as eco-friendly bioactive agents that can serve as a replacement for synthetic acaricides in controlling the population of $D$. farinae.
\end{abstract}

Keywords: clove oil; eugenol; nanofiber; microcapsules; house dust mites

\section{Introduction}

Currently-used synthetic acaricides, such as the pyrethroid species, pose risks to human health when exposed to the environment, or humans; one such issue is neurotoxicity [1]. Synthetic pyrethroids, which perform on $\mathrm{Na}^{+}$channels of the nerve cell membranes, can also have harmful effects on insects, such as honey bees [2]. In addition, these synthetic chemicals are hard to break down, so they build up quickly to a toxic point, which may present health risks to humans and the environment. Food quality protection acts recently restricted the sale of many commercial pyrethrum-based acaricides or pesticides [3]. This problem increases public pressure to provide safe or natural acaricides that have been produced in a more environmentally-friendly manner [3,4]. As a result, increased interest is now focused on more selective, natural compounds which are not toxic to humans and the environment, to reduce or eliminate reliance on synthetic acaricides or pesticides [5].

Natural essential oils are increasing in market demand due to their antimicrobial or acaricidal properties derived from the phenolic compounds of essential oils [6-9]. They have been studied as efficient, environmental-friendly, economic, and non-toxic acaricides to humans in the indoor environment [10-12]. The volatile properties of phenolic compounds, including alkanes, alcohols, aldehydes, and monoterpenoids displayed fumigant activities against a wide range of bacteria, fungi, and mites [13-15]. For example, essential oils, such as lavender, thyme, rosemary, marjoram, savory, and dillsun at $2 \mathrm{wt} \%$ and $1 \mathrm{wt} \%$ concentrations showed the mortality of greater than $97 \%$ and $95 \%$ on Varroa mites, respectively [16]. Additionally, $2 \mathrm{wt} \%$ spearmint demonstrated over $97 \%$ mortality on Varroa mites [16]. Cade, clove bud, coriander, horseradish, and mustard oils derived from plants at 
concentrations of $0.28 \mathrm{mg} \cdot \mathrm{cm}^{-2}$ showed $99 \%$ mortality against the poultry red mite, D. gallinae [15]. Thyme and pennyroyal oils have also been shown as effective acaricides against $D$. gallinae [17]. The derivate from Lauraceae tree [18], phenolic compounds derived from Chamaecyparis obtusa leaves [19], 3-methylphenol isolated from Ostericum koreanum [20], and Perilla oil [21] was reported to show an effect on house dust mites. Pennyroyal oil composed principally more than $97 \%$ pulegone showed a mortality of more than $98 \%$ against D. pteronyssinus at $0.025 \mu \mathrm{L} \cdot \mathrm{cm}^{-2}$ within a 5 min exposure time [22]. Furthermore, Kim et al. have studied the acaricidal effects of 56 natural plant essential oils on D. gallinae [15]. Among them, clove, thyme, horseradish, and coriander oils through direct contact and fumigation methods resulted in $100 \%$ mortality [15]. Additionally, other researchers reported that clove bud oil [6,23,24], thymol and cinnamaldehyde [25], and Cnidium officinale rhizome extracts [14] exhibited efficient mortality properties against D. farinae and D. pteronyssinus. Another example showed the major phenolic terpenoid components of essential oils, such as pulegone, $\alpha$-terpinene, $\beta$-terpinene, eucalyptol, menthone, linalool, and fenchone had an effect of up to $100 \%$ mortality on Tyrophagus putrescentiae [26].

However, most essential oils are volatile or easily oxidized [3,27]. For the practical use of essential oils as antimicrobial, acaricidal, or pestisidal agents, it is necessary to improve convenient handling and stability by means of microencapsulation, which has been widely used for encapsulating essential oils $[12,28,29]$. The population of house dust mites and their allergens are predominantly found in non-washable bedding, pillows, and upholstery home textiles, such as carpets and sofas [30]. In order to reduce exposure to mite allergens, it is significant to develop anti-mite fabrics from non-toxic resources to humans and the environment. However, no one has studied the encapsulation of clove oil, and its grafting to nylon nanofibers to control house dust mites in the indoor environment.

In this study, acaricidal nylon 66 nanofabrics (AN66Fs) were developed from natural and environmentally-friendly resources with the minimum toxicity to humans and the environment to control the population of $D$. farinae (common indoor house dust mite species). The first step was to produce clove oil-loaded microcapsules (COMCs) by the coacervation method and to electrospin nylon 66 nanofabrics. Subsequently, COMCs were grafted to nylon 66 nanofabrics from 0 to $25 \mathrm{wt} \%$ of COMCs. The second step was to evaluate the acaricidal activity of the AN66Fs in terms of COMCs loadings against $D$. farinae.

\section{Materials and Methods}

\subsection{Materials}

Clove bud oil (CO, grade $>99 \%$, density: $\left.1.04 \mathrm{~g} \cdot \mathrm{cm}^{-3}\right)$, Nile red dye, glutaraldehyde (GA, $25 \mathrm{wt} \%$ in water), poly(vinyl alcohol) (PVA, 35-50 kDa and $99 \mathrm{~mol} \%$ degree of hydrolysis), anhydrous sodium sulfate, nylon 66 pellets, formic acid (reagent grade $>95 \%$ ), and 4-(4,6-dimethoxy1,3,5-triazin-2-yl)-4-methylmorpholinium chloride (DMTMM) were purchased from Sigma Aldrich Co. (Wonsam-myeon, Gyeonggi-do, South Korea). House dust mite (Dermatophagoides farinae) and the nutrient mixture for mites were donated from the School of Agricultural Biotechnology, Seoul National University (Seoul, South Korea).

\subsection{Microencapsulation of COMCs by Oil-in-Water Simple Coacervation}

A $3 \%(w / v)$ PVA was dissolved in $100 \mathrm{~mL}$ deionized (DI) water at $80^{\circ} \mathrm{C}$ for $1 \mathrm{~h}$ and then cooled to room temperature $(\mathrm{RT})$. $\mathrm{CO}(10 \mathrm{~mL})$ was added to the PVA solution and homogenized using a homogenizer (Model-OV5, VELP Scientifica, Usmate, Italy) at $5000 \mathrm{rpm}$ for $20 \mathrm{~min}$ to produce a CO-PVA emulsion. Sodium sulfate in DI water $(15 \%(w / v))$ was added to the CO-PVA emulsion and then homogenized at $5000 \mathrm{rpm}$ for $10 \mathrm{~min}$. A crosslinking agent, $2 \mathrm{wt} \%$ glutaraldehyde (GA) of PVA, was gradually added to the CO-PVA emulsion and agitated at $1000 \mathrm{rpm}$ for $1 \mathrm{~h}$ above $50{ }^{\circ} \mathrm{C}$. Figure $1 \mathrm{a}$ shows the scheme of the microencapsulation procedure of COMCs and the PVA-GA crosslinking reaction to form acetal linkages in the shell of COMCs [31,32]. Afterwards, microcapsules were 
collected using a centrifuge (Model: HA-1000-3, Daegeon, Korea) at $5000 \mathrm{rpm}$ for 30 min and then washed with DI water containing $1 \mathrm{wt} \%$ ethanol a few times to eliminate any oil surrounding the COMCs and then freeze-dried for overnight.
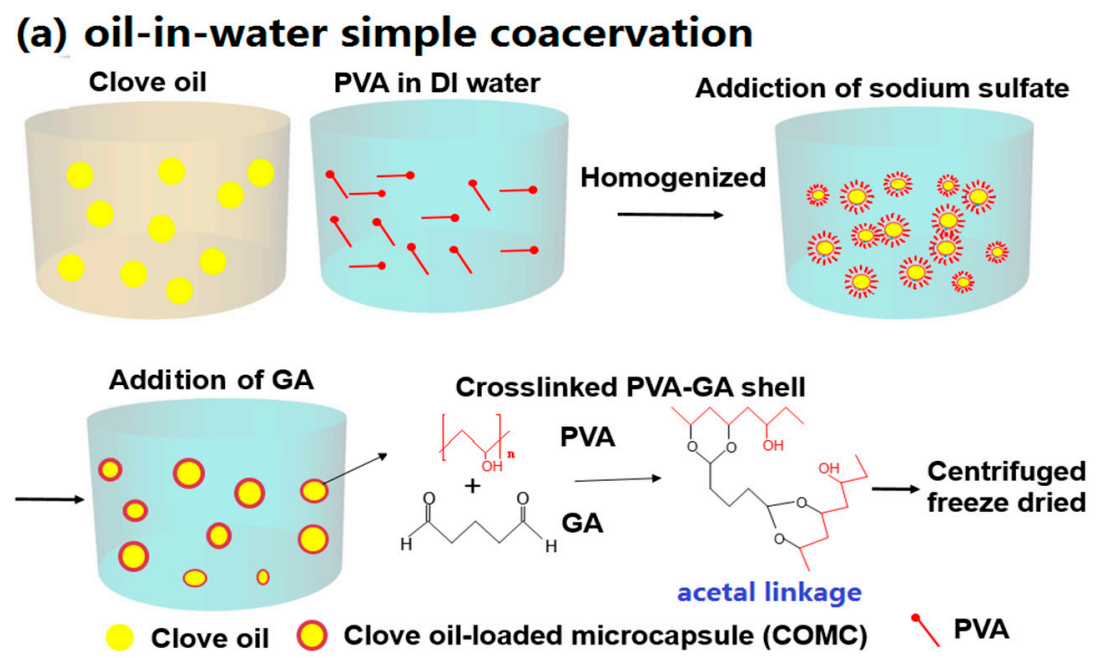

(b) Grafting process

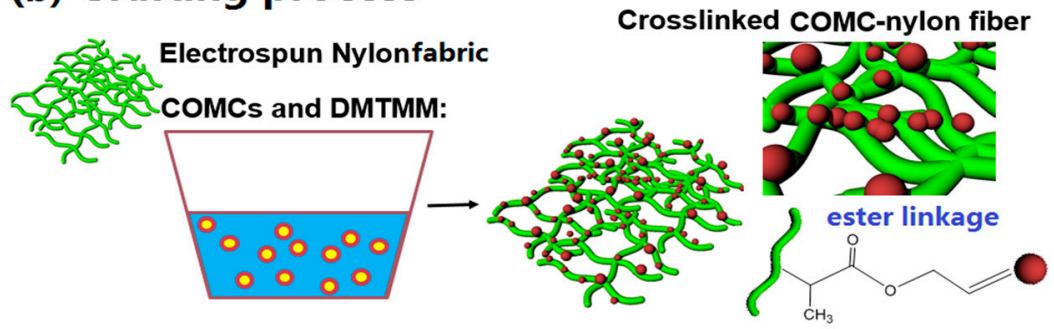

Figure 1. Scheme of the production of acaricidal nylon 66 nanofabrics (AN66Fs); (a) oil-in-water simple coacervation method to produce COMCs; and (b) the grafting procedure of nylon nanofibers with COMCs, the chemical reaction between carboxylic end groups of nylon 66 nanofibers and hydroxyl groups of PVA of COMCs form ester linkages.

\subsection{Analysis of the Core Loading of COMCs}

The CO loading within COMCs was quantified using a Clevenger-type apparatus. $10 \mathrm{~g}$ of freeze-dried COMCs was distilled for $3 \mathrm{~h}$ to isolate $\mathrm{CO}$ from COMCs while keeping the temperature above $250{ }^{\circ} \mathrm{C}$. The evaporated $\mathrm{CO}$ was chilled by cold water in the condenser of a Clevenger-type apparatus. Cooled $\mathrm{CO}$ was weighed and calculated for the core $\mathrm{CO}$ loading, compared to the original weight of COMCs. The average core loading was calculated with three replications each for the three different samples.

\subsection{The Internal Structure of COMCs}

In order to observe whether COMCs contain $\mathrm{CO}$ as a core material and well-formed shells with a pore-free surface, one drop of Nile Red dye was added to $\mathrm{CO}$, followed by the same microencapsulation procedure explained above in the experimental section. COMCs were observed using a confocal laser scanning microscope (CLSM; Leica TCS SL, Wetzlar, Germany) at $543 \mathrm{~nm}$ excitation wavelength, which was attached to $25 \mathrm{~mW}$ HeNe lasers with a $63 \times$ oil immersion lens (PlanApo 63× oil/1.40 NA/ $0.10 \mathrm{~mm}$ ). 


\subsection{Nylon 66 Nanofiber-Based Fabrics (Nylon Nanofabrics) through Electrospinning}

Nylon nanofabrics were produced using electrospinning. Initially, $10 \mathrm{wt} \%$ of nylon 66 pellets was dissolved into formic acid and stirred at $70{ }^{\circ} \mathrm{C}$ for $5 \mathrm{~h}$ on a hot plate. The cooled solution was added into a $5 \mathrm{~mL}$ syringe and then placed on the pump with a feeding rate of $500 \mu \mathrm{L}$ per hour. Twelve kilovolts was applied between the needle tip and the collector. After $10 \mathrm{~h}$, the randomly-oriented nylon nanofabrics were collected. A JEOL JSM-6340F field emission scanning electron microscope (FE-SEM, Hitachi, Japan) was used for observing the morphology of the nanofibers.

\subsection{Grafting of COMCs onto Nylon 66 Nanofibers}

The different loadings of COMCs at 0, 5, 10, 15, 20 and $25 \mathrm{wt} \%$ were suspended under stirring at $300 \mathrm{rpm}$ in $10 \mathrm{~mL}$ of DI water, and electrospun nanofabrics (size dimension: approximately $10 \times 10 \times$ $0.2 \mathrm{~cm})$ were immersed into each solution and DMTMM ( $2 \mathrm{wt} \%$ of COMCs $)$ as a condensing agent was added to catalyze chemical reactions as shown in Figure $1 \mathrm{~b}$. The solution bath was stirred at $50 \mathrm{rpm}$ for $6 \mathrm{~h}$ in order to complete further reaction. The crosslinking reactions occur between the hydroxyl groups of COMCs and carboxylic end groups of nylon 66 nanofibers, called the Fischer esterification reaction to form ester linkages chemically on nylon nanofibers [33-35]. Then the nanofabrics were removed from the solution. The AN66Fs were dried in oven for $12 \mathrm{~h}$ at RT. Fourier transform infrared spectroscopy (FTIR) equipped with a single-reflection attenuated total reflectance (ATR) system (Specac Ltd., London, UK) was used to characterize the surface chemical analysis of pure PVA, pure nylon 66 nanofabrics and AN66Fs with $15 \mathrm{wt} \%$ COMCs. Germanium was used for the ATR crystal $(2 \mathrm{~mm}$ in diameter; depth of penetration: $0.65 \mu \mathrm{m}$; refractive index 4.0).

The specimens were scanned from 4000 to $600 \mathrm{~cm}^{-1}$ wavenumbers with a resolution of $2 \mathrm{~cm}^{-1}$. A total of 256 scans were taken to increase the signal/noise ratio. A thermogravimetric analyzer (TGA, PerkinElmer Pyris 1, Waltham, MA, USA) was used for the pure nylon 66, pure PVA, neat clove bud oil, and AN66Fs containing 5, 10, 15, 20 and $25 \%$ COMCs in the temperature range of $25-750{ }^{\circ} \mathrm{C}$ under a nitrogen flow rate of $100 \mathrm{~mL} \cdot \mathrm{min}^{-1}$.

\subsection{The Acaricidal Effect of AN66Fs on D. farinae}

The acaricidal effect of AN66Fs was evaluated against D. farinae according to the American Association of Textile Chemists and Colorists (AATCC) test method 194-2007, Assessment of Anti-House Dust Mite Properties of Textiles. In the first step, AN66Fs at different loadings of COMCs and the control were cut into circular shapes of $5 \mathrm{~cm}$ diameter. Cut AN66Fs and 50 mites were placed into the Petri dish with $10 \mathrm{~cm}$ diameter. $50 \mathrm{mg}$ of nutrient mixture composed of albumin powder and dried yeast powder were put in each Petri dish. The edges of the Petri dishes were covered with a sticky gel and covered with micro-sized nylon mesh with a pore size under $50 \mu \mathrm{m}$ to prevent mites from escaping. All specimens were kept at $25^{\circ} \mathrm{C}$ and over $65 \%$ relative humidity. After $72 \mathrm{~h}$ treatment, the surviving $D$. farinae were counted under the optical microscope. All tests were conducted three times with three replicates. Dead HDM symptoms were characterized by immobility without walking or moving and shrunken legs. All specimens were counted at least twice. The following equation was used to determine the mortality of AN66Fs after $72 \mathrm{~h}$ :

$$
\operatorname{Mortality}(\%)=\frac{x-y}{x} \times 100
$$

where $x$ and $y$ are the numbers of $D$. farinae found on the control specimen and the AN66Fs specimen after exposure time, respectively.

\section{Results and Discussion}

The morphology and size distribution of COMCs are shown in Figure 2. Under SEM observation, COMCs show spherical shapes and pore-free surfaces with a widespread size distribution. Figure $2 b$ 
shows the diameter distribution histogram of COMCs measured from randomly-selected areas of SEM images $(\mathrm{N} \geq 500)$. While the diameters of COMCs range between 0.2 and $8.5 \mu \mathrm{m}$, the average diameter is about $2.9 \mu \mathrm{m}$. COMCs demonstrated aggregation due to the uncrosslinked PVA residue present on the shell surface of COMCs [36]. The hydrocarbon part $\left(\mathrm{CH}_{2} \mathrm{CH}\right)$ of the PVA chains were possibly adsorbed onto the oil surface of COMCs, whereas the hydroxyl groups -OH) of PVA allowed the COMC microcapsules to adhere together to promote aggregation by hydrogen bonding. The broken COMCs have a diameter of $2.6 \mu \mathrm{m}$ and shell thickness of approximately $0.35 \mu \mathrm{m}$, which presents about $65 \mathrm{vol} \%$ of clove oil (CO) as the core loading presented in Figure 2c.
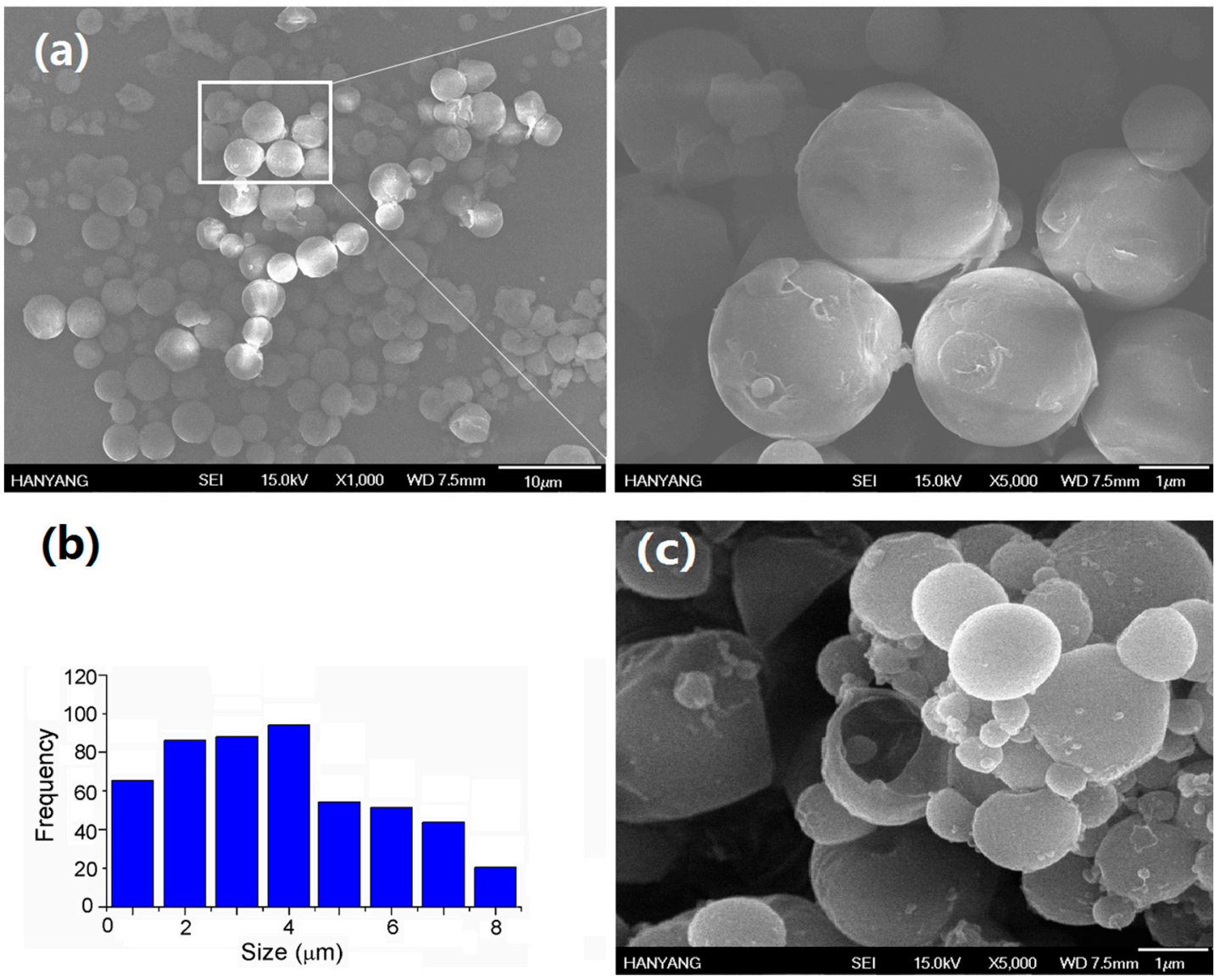

Figure 2. The size analysis of COMCs produced by the oil-in-water simple coacervation method; (a) the morphology of COMCs; (b) the size distribution histogram of COMCs; and (c) the broken COMC with shell thickness of $0.35 \mu \mathrm{m}$.

Further evidence shows the internal structures of COMCs are obtained from CLSM. Figure 3 shows CLSM images showing the internal structures of COMCs. A brightfield image of COMCs confirms their spherical shape, free of voids with well-formed shells, ranging from a few hundred nanometers to a few micrometers, as shown in Figure 3a. For example, a COMC with a diameter of $4.5 \mu \mathrm{m}$ and shell thickness of approximately $0.8 \mu \mathrm{m}$ indicates that the core (clove oil) occupied about $65 \mathrm{vol} \%$ of the COMC. The results confirm the observations by SEM that COMCs have similar oil loading and a very wide size distribution. Figure $3 \mathrm{~b}$ shows a fluorescence image of COMCs. The existence of clove oil stained with Nile Red is observed in red color. The oil loading of COMCs quantified by the distillation method was found to have $51 \pm 4.8 \%$ by weight. 

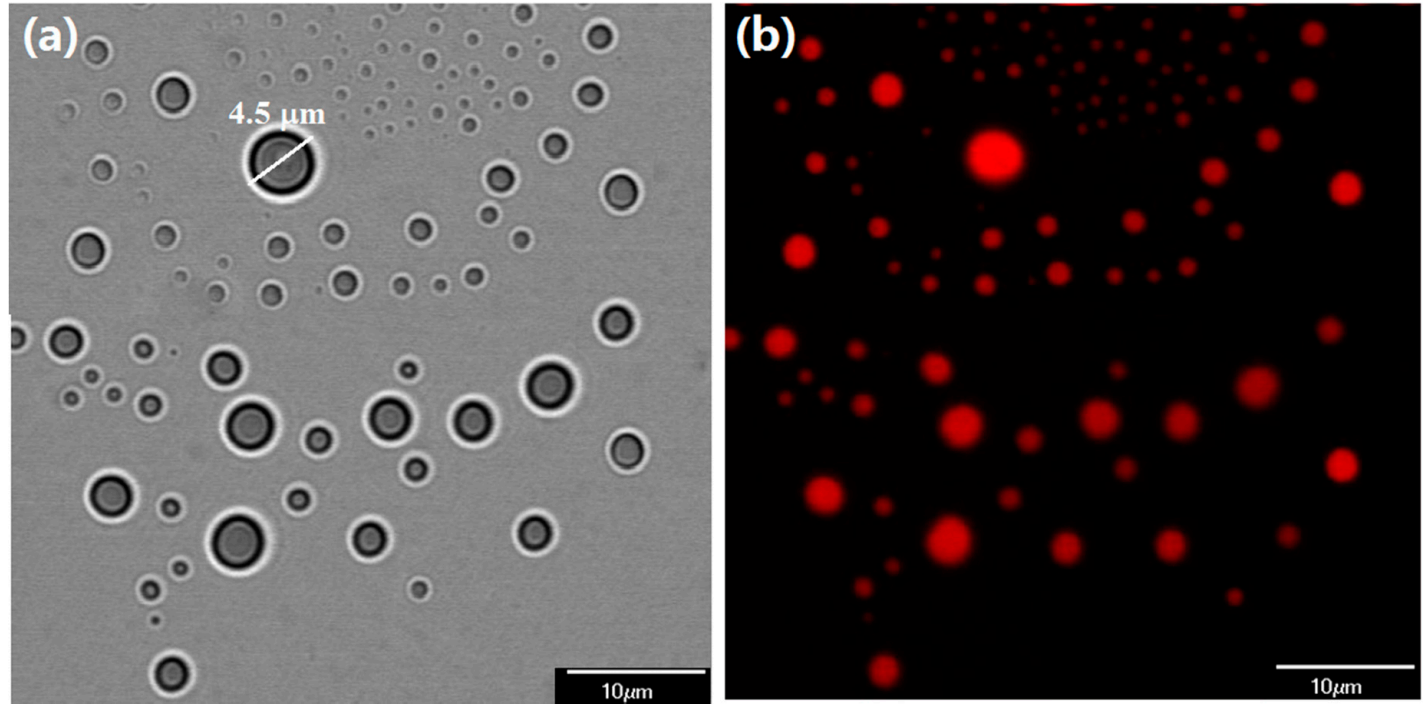

Figure 3. CLSM images showing the internal structure of COMCs; (a) a brightfield image; and (b) a fluorescent image (red color corresponds to clove oil stained with Nile red as the core loading).

After grafting COMCs to nanofabrics at different loadings of COMCs at 5, 10, 15, 20 and $25 \mathrm{wt} \%$, the morphology of AN66Fs was observed by SEM. The diameters of nylon nanofibers range from $50 \mathrm{~nm}$ to $4.3 \mu \mathrm{m}$. Figure $4 \mathrm{a}-\mathrm{f}$ show that COMCs are chemically attached to nylon nanofibers with increased loading of COMCs from 5 to $25 \mathrm{wt} \%$. The chemical bonding on the nanofibers is because hydroxyl groups from unreacted PVA shells can crosslink chemically with carboxylic end groups on nylon nanofibers to produce ester linkages. These ester linkages increase the interfacial bonding between nylon nanofibers and COMCs. Hence, COMCs can break easily and allow the release of clove oil under friction and pressure of nanofabrics. Figure 4a shows neat electrospun nylon nanofibers without capsules. Figure $4 \mathrm{~b}$ represents AN66Fs containing $5 \mathrm{wt} \%$ COMCs and displays the individual microcapsules attached to each nanofiber without aggregation of COMCs. Figure 4c,d show AN66Fs containing $10 \mathrm{wt} \%$ and $15 \mathrm{wt} \%$ of COMCs, respectively, and display well-dispersed COMCs on the nanofibers. However, the increasing COMC loadings over $15 \mathrm{wt} \%$, increased the aggregates of COMCs on the nanofibers, as well as decreased the pores of AN66Fs, as shown in Figure $4 \mathrm{~d}-\mathrm{f}$. There is a broken capsule which releases clove oil, as shown in Figure 4e. In the case of AN66Fs containing $20 \mathrm{wt} \%$ and $25 \mathrm{wt} \%$ COMCs, they show small pores due to the cluster of COMCs on the surface, and seem like coatings or films, as shown in Figure 4e,f.
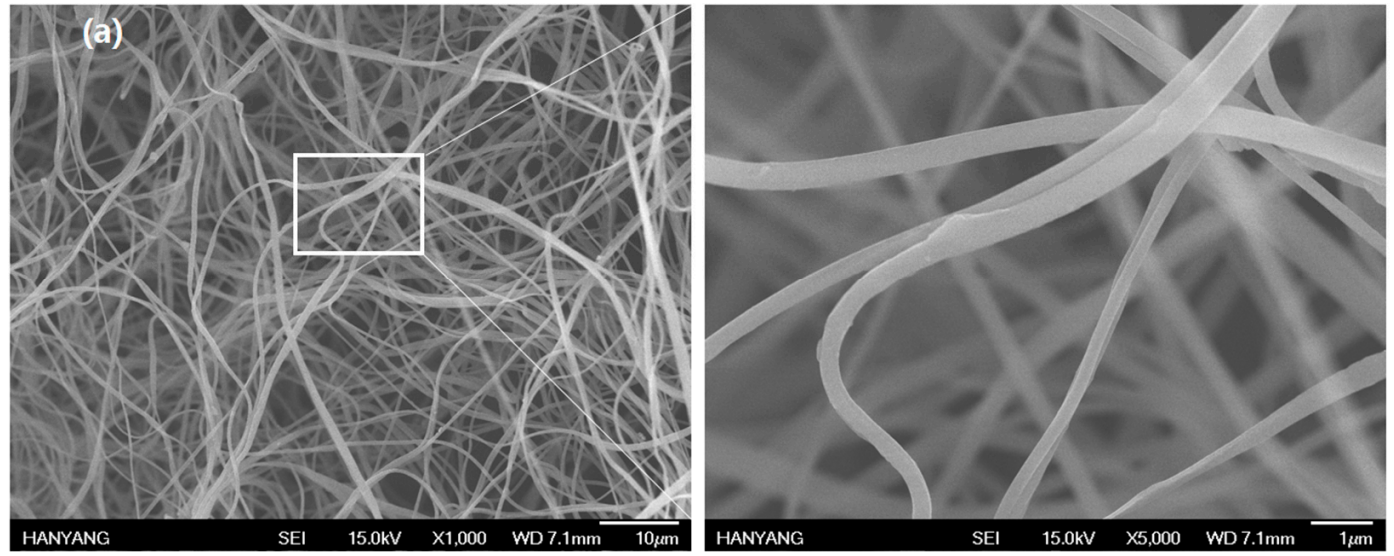

Figure 4. Cont. 

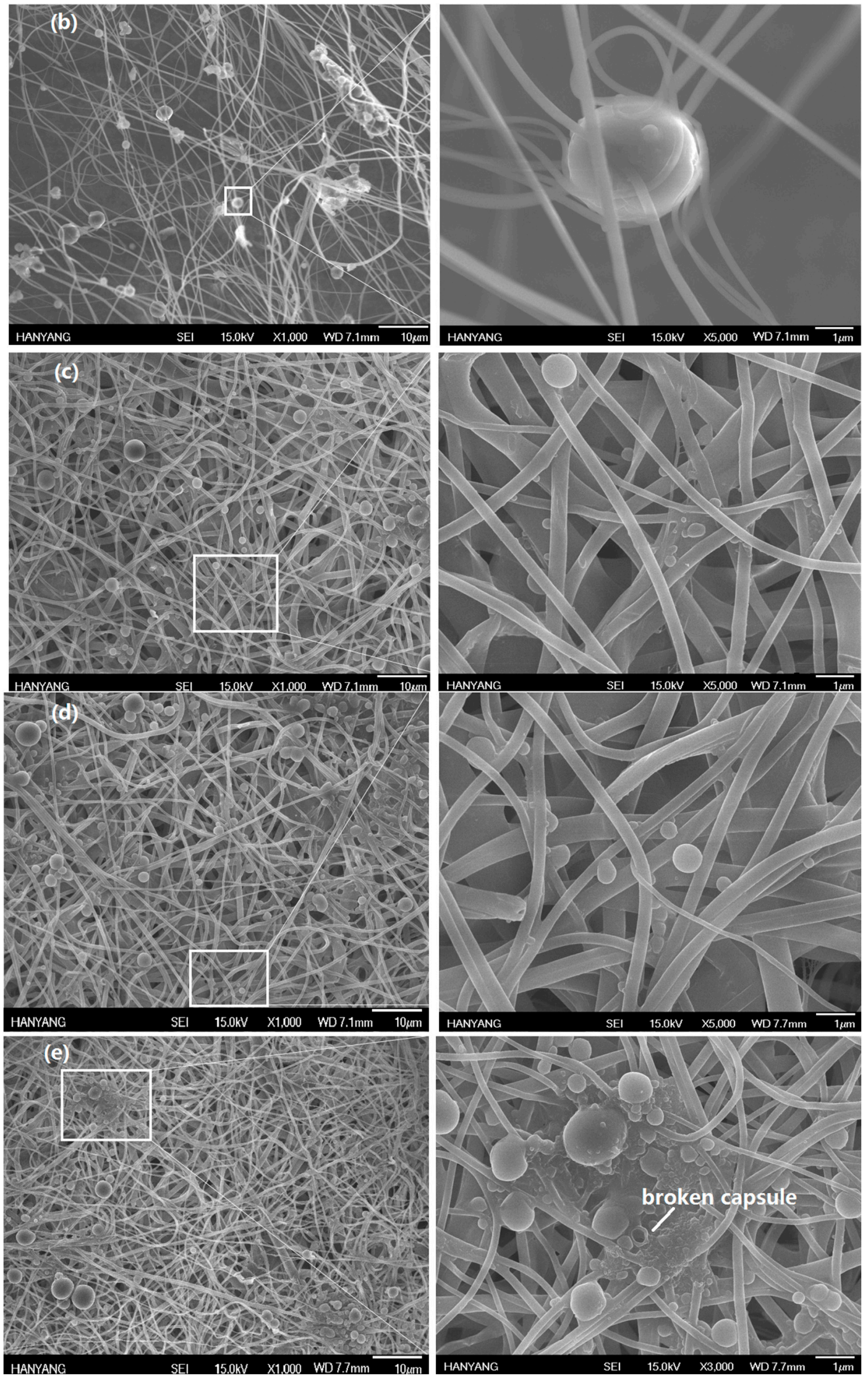

Figure 4. Cont. 

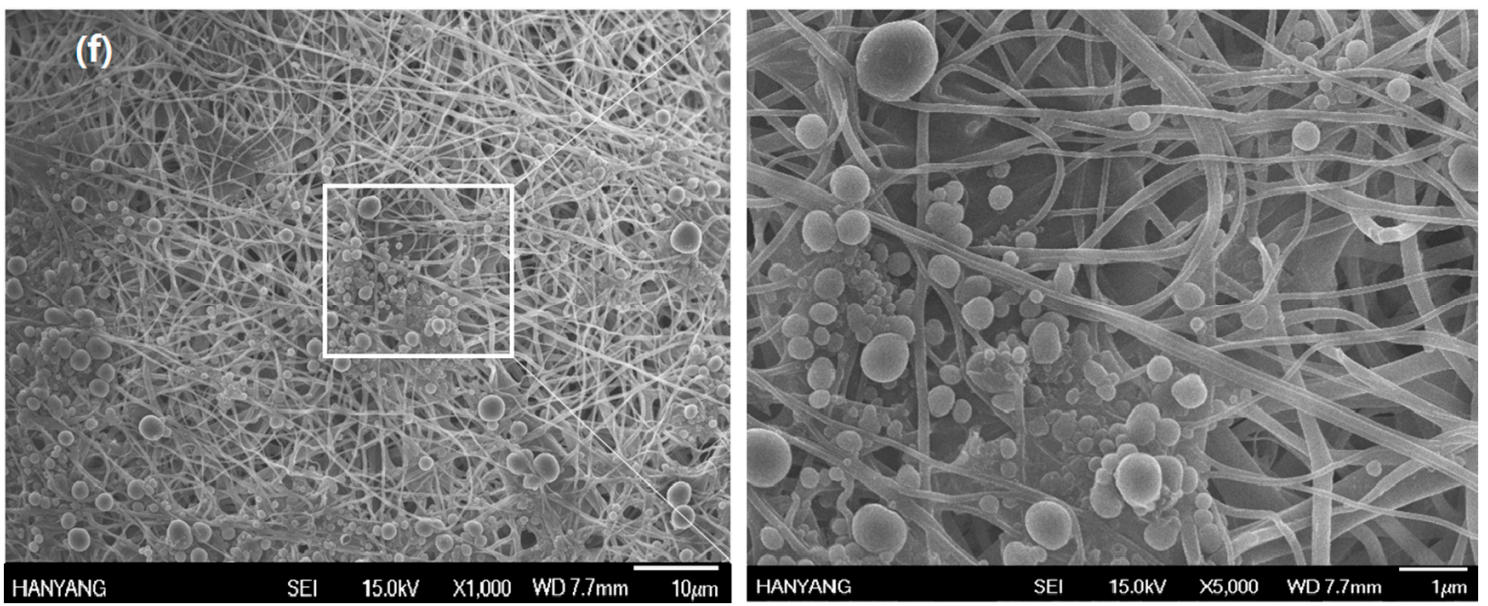

Figure 4. SEM images of AN66Fs at different loadings of COMCs; (a) 0 wt \%; (b) 5 wt \%; (c) 10 wt \%; (d) $15 \mathrm{wt} \%$; (e) $20 \mathrm{wt} \%$ and (f) $25 \mathrm{wt} \%$.

Figure 5 shows ATR-FTIR spectra of pure PVA, pure nylon nanofabric and AN66Fs at $15 \mathrm{wt} \%$ COMCs. The FTIR spectrum of pure PVA shows the absorption associated with the $\mathrm{C}-\mathrm{H}$ alkyl stretching band in the $2850-3000 \mathrm{~cm}^{-1}$ range. Strong hydroxyl groups for free hydroxyl (-OH stretching band) exists between 3000 and $3650 \mathrm{~cm}^{-1}$ [37]. Pure nylon nanofabric shows the absorption peaks at 2750-2980 $\mathrm{cm}^{-1}$ range (asymmetric $\mathrm{C}-\mathrm{H}$ and $\mathrm{CH}_{2}$ stretching), $1120 \mathrm{~cm}^{-1}, 2250 \mathrm{~cm}^{-1}$ and $2494 \mathrm{~cm}^{-1}$ (symmetric $\mathrm{CH}$ and $\mathrm{CH}_{2}$ stretching), and $1474 \mathrm{~cm}^{-1}$ (N-H deformation). Nylon 66 nanofabric has additional peaks at 1640 and $1554 \mathrm{~cm}^{-1}$ corresponding to amide groups, and $\mathrm{C}=\mathrm{O}$ and $\mathrm{C}-\mathrm{N}$ stretching from amide groups [38]. Similar IR absorption peaks have been observed by other researchers for nylon 66 fabrics [39]. In the case of AN66Fs, the crosslinked PVA-GA shell of COMCs shows the unique peak corresponding to $\mathrm{C}-\mathrm{O}$ stretching at approximately $1135 \mathrm{~cm}^{-1}$, which can be attributed to the acetal linkages $(\mathrm{C}-\mathrm{O}-\mathrm{C})$ [31]. The $\mathrm{O}-\mathrm{H}$ stretching vibration peak in the range between 2600 and $3200 \mathrm{~cm}^{-1}$ was decreased, compared to pure PVA. The relative increase of the $\mathrm{C}=\mathrm{O}$ band of ester linkages by the crosslinking reactions between -OH of PVA and - $\mathrm{COOH}$ end group of nylon 66 fibers at $1740 \mathrm{~cm}^{-1}$ was observed [31,37].

Figure 6 shows TGA thermograms of pure nylon 66, pure PVA, neat clove bud oil and AN66Fs containing 5, 10, 15, 20 and 25\% COMCs. TGA measures changes in the weight loss of AN66Fs containing different loadings of COMCs in the temperature range of $25-750{ }^{\circ} \mathrm{C}$. Neat clove bud oil loses $100 \%$ of its weight when the temperature reaches $220^{\circ} \mathrm{C}$, while pure nylon 66 nanofabric undergoes thermal degradation beginning at $480^{\circ} \mathrm{C}$ and finishing at $600{ }^{\circ} \mathrm{C}$ with a total mass loss of $99 \%$. Pure PVA shows degradation points of $280{ }^{\circ} \mathrm{C}$ and $400{ }^{\circ} \mathrm{C}$. The residual weight at $300{ }^{\circ} \mathrm{C}$ indicates the remaining nylon nanofabric and PVA since clove oil loses its weight completely at around $220{ }^{\circ} \mathrm{C}$. From the results, higher residual weight at $300{ }^{\circ} \mathrm{C}$ matches less grafting loading of capsules onto nanofabrics. AN66Fs containing 25\% COMCs show the highest weight reduction which indicates more capsules onto nanofabrics. AF66Fs with 5\% COMCs show the lowest weight reduction, which means the fewest capsules grafting onto nanofabrics. 


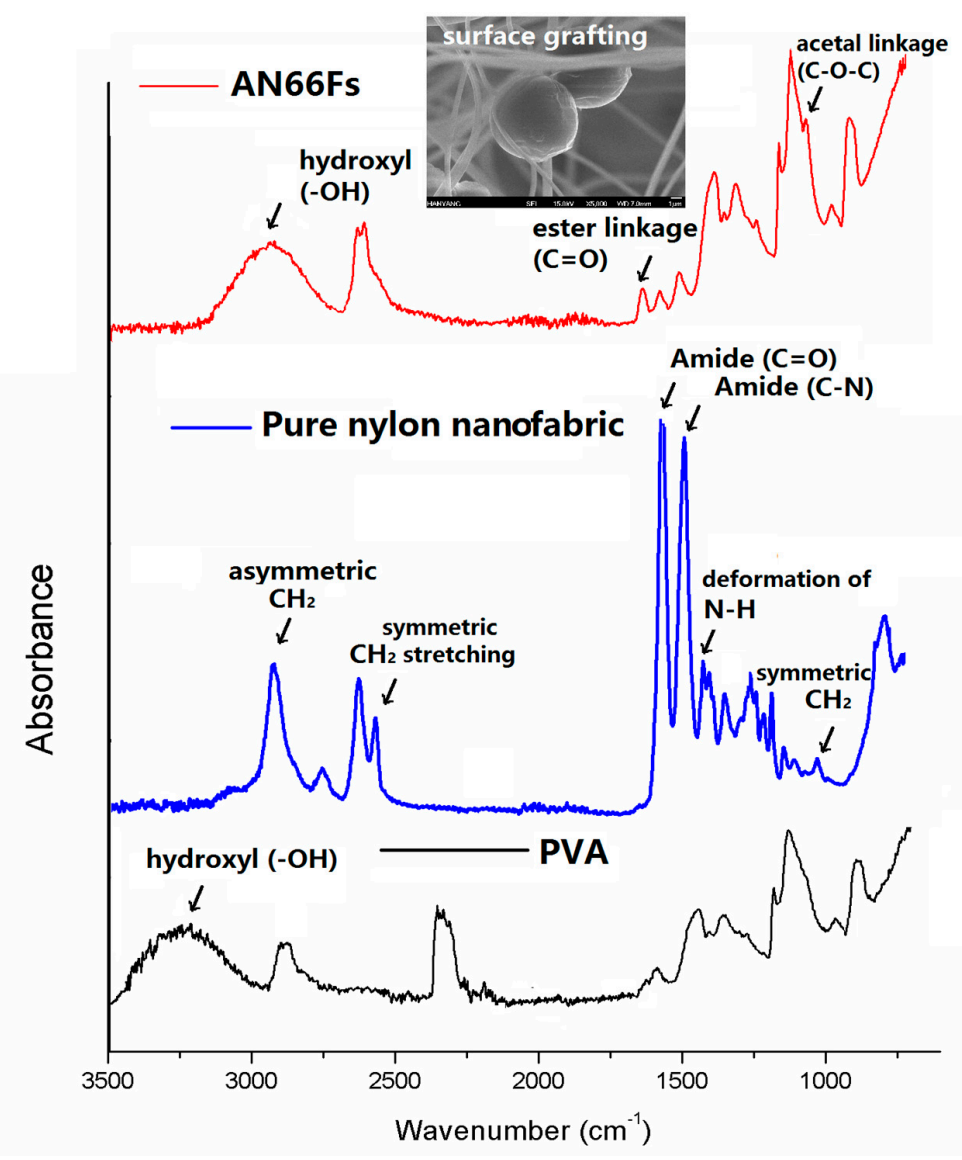

Figure 5. ATR-FTIR spectra of pure PVA, nylon 66 nanofabric, and AN66Fs.

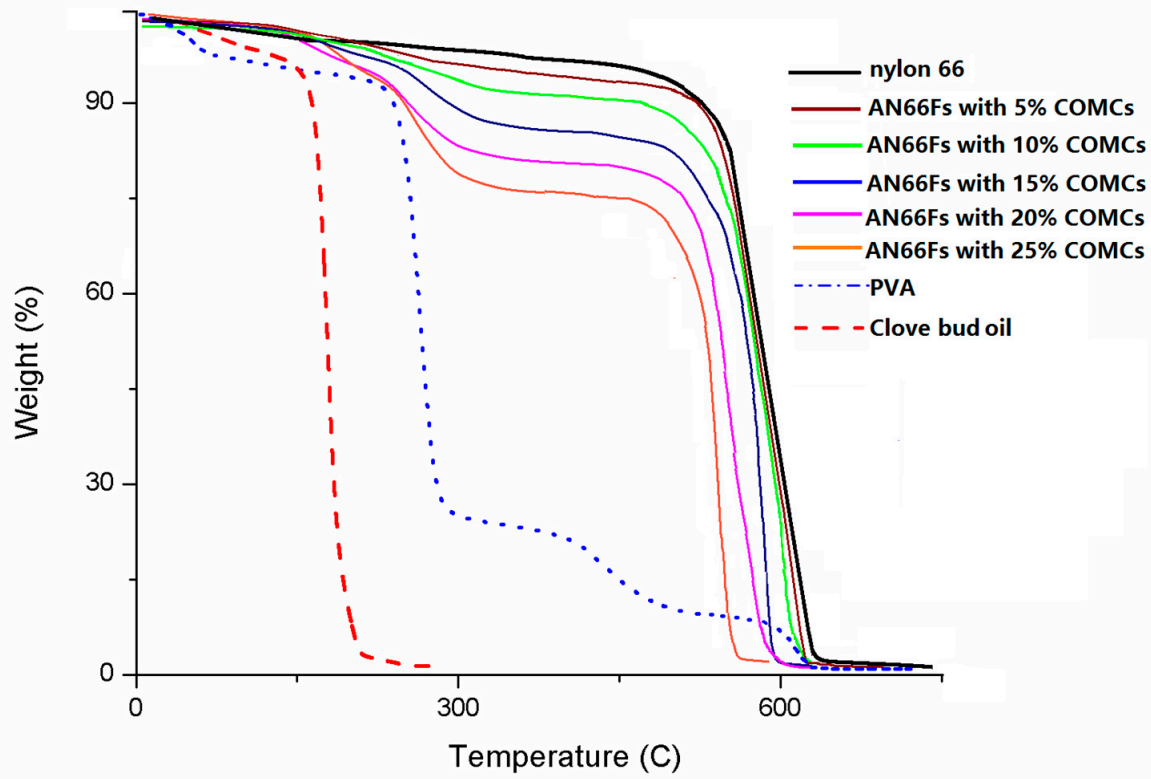

Figure 6. TGA thermograms of pure nylon 66, pure PVA, neat clove bud oil, and AN66Fs with 5, 10, 15, 20 and $25 \%$ COMCs. 
The mortality tests were conducted to evaluate the acaricidal effect of AN66Fs at different loadings from 0 to $25 \mathrm{wt} \%$ against $D$. farinae. All specimens were effective in reducing the number of $D$. farinae after $72 \mathrm{~h}$ treatment as shown in Table 1. In general, the mortality increased with an increase in COMCs loading to AN66Fs. The increase in COMCs loading to AN66Fs from 5 to 15 wt \% greatly reduced the number of $D$. farinae from $22 \%$ to $93 \%$. However, COMCs loading of over 20 wt $\%$ showed $100 \%$ mortality after $72 \mathrm{~h}$. After $1 \mathrm{~h}$ of exposure time to AN66Fs with different loadings from 0 to $25 \mathrm{wt} \%$, the number of surviving D. farinae resulted in less than $20 \%$ mortality. AN66Fs at $20 \mathrm{wt} \%$ and $25 \mathrm{wt} \%$ show nearly 100\% mortality within $24 \mathrm{~h}$, compared to AN66Fs (15 wt \% COMCs loading) with only $72 \%$ mortality. This acaricidal activity is due to the hydrophobic property of clove oil, which plays a critical role in reducing the population of $D$. farinae. In addition, clove oil composed of more than $75 \%$ eugenol, which identified the phenolic monoterpenoid, exhibits powerful acaricidal activity [23,40]. The allyl group-derived eugenol may give stable non-ionic structure during the microencapsulation process [24,41]. Furthermore, clove oil is revealed as a plant-derived phenylpropanoid, which showed structural advantages in defense functions against microbial attack [42].

Table 1. In vitro mortality tests of AN66Fs at 0, 5, 10, 15, 20 and 25 wt \% COMCs loadings against D. farinae after $72 \mathrm{~h}$ with three replications.

\begin{tabular}{ccccccc}
\hline COMCs Loading to Nylon Nanofabrics & $\mathbf{0} \mathbf{w t} \mathbf{\%}$ & $\mathbf{5} \mathbf{w t} \%$ & $\mathbf{1 0} \mathbf{w t} \%$ & $\mathbf{1 5} \mathbf{w t} \mathbf{\%}$ & $\mathbf{2 0} \mathbf{w t} \mathbf{\%}$ & $\mathbf{2 5} \mathbf{w t} \mathbf{~}$ \\
\hline Surviving Number of D. farinae after 72 h & $50(0.2)$ & $39(1.6)$ & $18(2.2)$ & $4(0.8)$ & $1(0.5)$ & $0(0)$ \\
Mortality (\%) & $0.1(0)$ & $22(1.8)$ & $64(2.5)$ & $93(2.4)$ & $100(0.5)$ & $100(0)$ \\
\hline
\end{tabular}

Values in parentheses represent standard deviation.

In Figure 7a, the unpoisoned adult-sized D. farinae is shown in the range of 200 to $300 \mu \mathrm{m}$ in length. Figure $7 \mathrm{~b}$ shows the poisoning symptom of $D$. farinae from treated fabrics with COMCs. It shows a knockdown-type death with desiccation on the body of D. farinae. Similar results were reported by Ignatowicz et al. and Kim et al. that dead T. putrescentiae by monoterpenoids showed depression of the dorsal surface as an idiosoma symptom related to be desiccation after shriveling, with legs folded under their bodies $[43,44]$. However, synthetic insecticides, such as pyrethroids, showed uncoordinated behavior or hollow skin surfaces after treatment [23]. In the present study, D. farinae showed forward leg movement and desiccation symptoms as their unique initial non-toxic signs induced by natural monoterpenoid resources. The results demonstrate that clove bud oil compounds possess acaricidal activityies by vapor action when COMCs break and release the bioactive (clove oil) on the fabrics. Eugenol, as the monoterpenoid containing hydroxyl groups in its structure, allows for greater water release from the body of $D$. farinae, thus supporting greater acaricidal activity resulting from desiccation [26]. The nanofabric grafted with $10 \mathrm{wt} \%$ COMCs shows $64 \%$ mortality. This finding may be attributed to insufficient loading of COMCs to inhibit $D$. farinae. A major reason for low mortality (64\%) in nanofabrics with $10 \mathrm{wt} \%$ COMCs loading is that the COMCs remained unbroken due to their aggregated shape, as shown in Figure 7c. In addition, the low grafting yield of COMCs onto nanofabrics may limit the acaricidal effect on $D$. farinae due to limited chemical bonding sites between nylon 66 nanofibers and COMCs. 

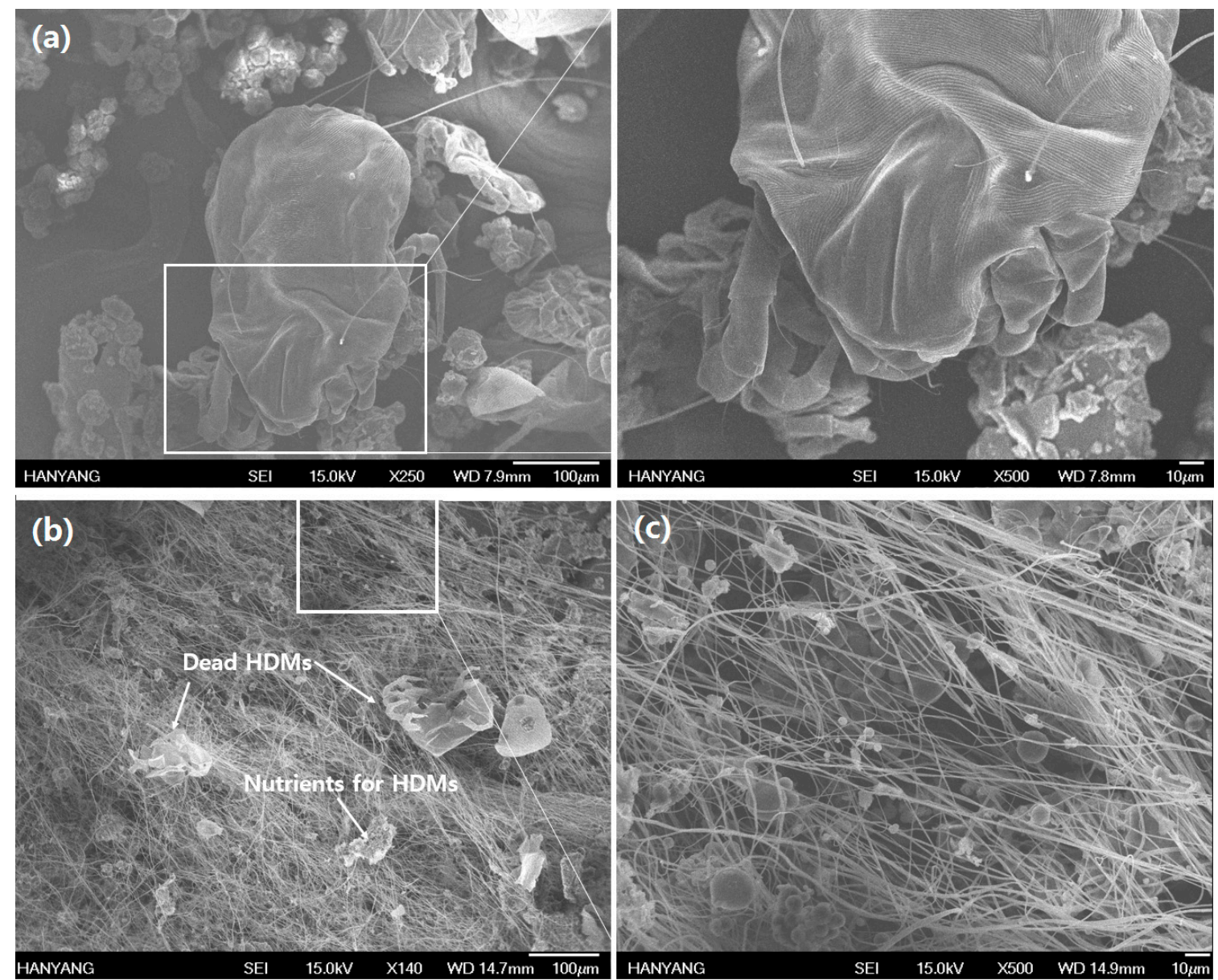

Figure 7. In vitro mortality tests of AN66Fs at $10 \mathrm{wt} \% \mathrm{COMCs}$ after $72 \mathrm{~h}$ exposure of $D$. farinae; (a) the unpoisoned adult-sized D. farinae; (b) a knockdown-type of dead adult HDM with desiccation; and (c) aggregated COMCs on the nanofibers.

\section{Conclusions}

In this study, nanofabrics grafted with COMCs showed excellent acaricidal activity and the possibility to reduce allergen levels and clinical symptoms of house dust mite allergy in the household environment. Our results showed that the diameters of COMCs range between 0.1 and $8.5 \mu \mathrm{m}$, with the average diameter equaling $2.9 \mu \mathrm{m}$. The core loading $(\mathrm{CO})$ was found to have about $65 \mathrm{vol} \%$. When incorporated into textiles, such as beddings, home and medical textiles, the nanofabrics grafted with COMCs could be efficient acaricidal agents to reduce the population of $D$. farinae. The release of clove oil from COMCs had an effect on $D$. farinae because of eugenol, a stable allyl-derived structure, and served as a natural acaricidal agent. The increase in COMCs loading to nanofabrics from 5 to $15 \mathrm{wt} \%$ effectively reduced the number of $D$. farinae from $22 \%$ to $93 \%$. However, COMC loadings of over $20 \mathrm{wt} \%$ showed $100 \%$ mortality within $24 \mathrm{~h}$. This research presents the use of clove oil through a microencapsulation technique and grafting procedure on nanofabrics, showing practical usage in real life, therefore, serving as the replacement for synthetic or conventional acaricides. Due to its low toxicity, nylon 66 nanofabrics grafted with COMCs pose little risk to humans and the environment.

Acknowledgments: This research was supported by Basic Science Research Program through the National Research Foundation of Korea (NRF) funded by the Ministry of Education (NRF-2016R1A6A1A03013422).

Author Contributions: Joo Ran Kim performed the experiments and Seong Hun Kim directed the research and performed the data analysis. Both authors were responsible for writing the manuscript. 
Conflicts of Interest: The authors declare no conflict of interest.

\section{References}

1. Wahida, L.; Aribi, N.; Soltani, N. Evaluation of secondary effects of some acaricides on apis mellifera intermissa (hymenoptera, apidae): Acetylcholinesterase and glutathione S-transferase activities. Eur. J. Sci. Res. 2008, 21, 642-649.

2. Romi, R.; Lo Nostro, P.; Bocci, E.; Ridi, F.; Baglioni, P. Bioengineering of a cellulosic fabric for insecticide delivery via grafted cyclodextrin. Biotechnol. Prog. 2005, 21, 1724-1730. [CrossRef] [PubMed]

3. Isman, M.B. Plant essential oils for pest and disease management. Crop Prot. 2000, 19, 603-608. [CrossRef]

4. Huang, P.K.; Lin, S.X.; Tsai, M.J.; Leong, M.; Lin, S.R.; Kankala, R.; Lee, C.H.; Weng, C.F. Encapsulation of 16-Hydroxycleroda-3,13-Dine-16,15-Olide in mesoporous silica nanoparticles as a natural dipeptidyl peptidase-4 inhibitor potentiated hypoglycemia in diabetic mice. Nanomaterials 2017, 7, 112. [CrossRef] [PubMed]

5. Dorman, H.J.; Deans, S.G. Antimicrobial agents from plants: Antibacterial activity of plant volatile oils. J. Appl. Microbiol. 2000, 88, 308-316. [CrossRef] [PubMed]

6. Saad, E.-Z.; Hussien, R.; Saher, F.; Ahmed, Z. Acaricidal activities of some essential oils and their monoterpenoidal constituents against house dust mite, Dermatophagoides pteronyssinus (acari: Pyroglyphidae). J. Zhejiang Univ. Sci. B 2006, 7, 957-962. [CrossRef] [PubMed]

7. Kung, M.L.; Lin, P.Y.; Hsieh, C.W.; Tai, M.H.; Wu, D.C.; Kuo, C.H.; Hsieh, S.L.; Chen, H.T.; Hsieh, S. Bifunctional peppermint oil nanoparticles for antibacterial activity and fluorescence imaging. ACS Sustain. Chem. Eng. 2014, 2, 1769-1775. [CrossRef]

8. Wei, M.C.; Lin, P.H.; Hong, S.J.; Chen, J.M.; Yang, Y.C. Development of a green alternative procedure for the simultaneous separation and quantification of clove oil and its major bioactive constituents. ACS Sustain. Chem. Eng. 2016, 4, 6491-6499. [CrossRef]

9. Zhang, W.; Ronca, S.; Mele, E. Electrospun nanofibres containing antimicrobial plant extracts. Nanomaterials 2017, 7, 42. [CrossRef] [PubMed]

10. Tovey, E.R.; McDonald, L.G. A simple washing procedure with eucalyptus oil for controlling house dust mites and their allergens in clothing and bedding. J. Allergy Clin. Immunol. 1997, 100, 464-466. [CrossRef]

11. Liakos, I.L.; Holban, A.M.; Carzino, R.; Lauciello, S.; Grumezescu, A. Electrospun fiber pads of cellulose acetate and essential oils with antimicrobial activity. Nanomaterials 2017, 7, 84. [CrossRef] [PubMed]

12. Kim, J.R. Eucalyptus oil-loaded microcapsules grafted to cotton fabrics for acaricidal effect against dermatophagoides farina. J. Microencapsul. 2017, 34, 1-22. [CrossRef] [PubMed]

13. Rice, P.J.; Coats, J.R. Insecticidal properties of several monoterpenoids to the house fly (diptera: Muscidae), red flour beetle (coleoptera: Tenebrionidae), and southern corn rootworm (coleoptera: Chrysomelidae). J. Econ. Entomol. 1994, 87, 1172-1179. [CrossRef] [PubMed]

14. Kwon, J.H.; Ahn, Y.J. Acaricidal activity of butylidenephthalide identified in cnidium officinale rhizome against dermatophagoides farinae and dermatophagoides pteronyssinus (acari: Pyroglyphidae). J. Agric. Food Chem. 2002, 50, 4479-4483. [CrossRef] [PubMed]

15. Kim, S.I.; Yi, J.H.; Tak, J.H.; Ahn, Y.J. Acaricidal activity of plant essential oils against dermanyssus gallinae (acari: Dermanyssidae). Vet. Parasitol. 2004, 120, 297-304. [CrossRef] [PubMed]

16. Ariana, A.; Ebadi, R.; Tahmasebi, G. Laboratory evaluation of some plant essences to control varroa destructor (acari: Varroidae). Exp. Appl. Acarol. 2002, 27, 319-327. [CrossRef] [PubMed]

17. Smith, T.J.; George, D.R.; Sparagano, O.A.; Seal, C.; Shiel, R.S.; Guy, J.H. A pilot study into the chemical and sensorial effect of thyme and pennyroyal essential oil on hens eggs. Int. J. Food Sci. Technol. 2009, 44, 1836-1842. [CrossRef]

18. Furuno, T.; Terada, Y.; Yano, S.; Uehara, T.; Jodai, S. Activities of leaf oils and their components from lauraceae trees against house dust mites. J. Jpn. Wood Res. Soc. 1994, 40, 78-87.

19. Jang, Y.S.; Lee, C.H.; Kim, M.K.; Kim, J.H.; Lee, S.H.; Lee, H.S. Acaricidal activity of active constituent isolated in Chamaecyparis obtusa leaves against Dermatophagoides spp. J. Agric. Food Chem. 2005, 53, 1934-1937. [CrossRef] [PubMed] 
20. Jeon, J.H.; Yang, J.Y.; Chung, N.; Lee, H.S. Contact and fumigant toxicities of 3-methylphenol isolated from Ostericum koreanum and its derivatives against house dust mites. J. Agric. Food Chem. 2012, 60, 12349-12354. [CrossRef] [PubMed]

21. Sanbongi, C.; Takano, H.; Osakabe, N.; Sasa, N.; Natsume, M.; Yanagisawa, R.; Inoue, K.-I.; Sadakane, K.; Ichinose, T.; Yoshikawa, T. Rosmarinic acid in perilla extract inhibits allergic inflammation induced by mite allergen, in a mouse model. Clin. Exp. Allergy 2004, 34, 971-977. [CrossRef] [PubMed]

22. Rim, I.S.; Jee, C.H. Acaricidal effects of herb essential oils against Dermatophagoides farinae and D. pteronyssinus (acari: Pyroglyphidae) and qualitative analysis of a herb Mentha pulegium (pennyroyal). Korean J. Parasitol. 2006, 44, 133-138. [CrossRef] [PubMed]

23. Kim, E.H.; Kim, H.K.; Ahn, Y.J. Acaricidal activity of clove bud oil compounds against Dermatophagoides farinae and Dermatophagoides pteronyssinus (acari: Pyroglyphidae). J. Agric. Food Chem. 2003, 51, 885-889. [CrossRef] [PubMed]

24. Myint, S.; Wan Daud, W.R.; Mohamad, A.B.; Kadhum, A.A.H. Gas chromatographic determination of eugenol in ethanol extract of cloves. J. Chromatogr. B Biomed. Sci. Appl. 1996, 679, 193-195. [CrossRef]

25. Deans, S.; Ritchie, G. Antibacterial properties of plant essential oils. Int. J. Food Microbiol. 1987, 5, $165-180$. [CrossRef]

26. Sánchez-Ramos, I.; Castañera, P. Acaricidal activity of natural monoterpenes on Tyrophagus putrescentiae (schrank), a mite of stored food. J. Stored Prod. Res. 2000, 37, 93-101. [CrossRef]

27. Liang, Y.; Guo, M.; Fan, C.; Dong, H.; Ding, G.; Zhang, W.; Tang, G.; Yang, J.; Kong, D.; Cao, Y. Development of novel urease-responsive pendimethalin microcapsules using silica-IPTS-PEI as controlled release carrier materials. ACS Sustain. Chem. Eng. 2017, 5. [CrossRef]

28. Fong, J. Microencapsulation by solvent evaporation and organic phase separation processes. Control. Release Syst. 1988, 1, 81-108.

29. Li, Y.; Zhou, M.; Pang, Y.; Qiu, X. Lignin-based microsphere: Preparation and performance on encapsulating the pesticide avermectin. ACS Sustain. Chem. Eng. 2017, 5, 3321-3328. [CrossRef]

30. Thomas, W.; Smith, W. House-dust-mite allergens. Allergy 1998, 53, 821-832. [CrossRef] [PubMed]

31. Dos Reis, E.F.; Campos, F.S.; Lage, A.P.; Leite, R.C.; Heneine, L.G.; Vasconcelos, W.L.; Lobato, Z.I.P.; Mansur, H.S. Synthesis and characterization of poly (vinyl alcohol) hydrogels and hybrids for rMPB70 protein adsorption. Mater. Res. 2006, 9, 185-191. [CrossRef]

32. Leimann, F.V.; Gonçalves, O.H.; Machado, R.A.; Bolzan, A. Antimicrobial activity of microencapsulated lemongrass essential oil and the effect of experimental parameters on microcapsules size and morphology. Mater. Sci. Eng. C 2009, 29, 430-436. [CrossRef]

33. Fang, D.; Zhou, X.L.; Ye, Z.W.; Liu, Z.L. Brønsted acidic ionic liquids and their use as dual solvent-catalysts for fischer esterifications. Ind. Eng. Chem. Res. 2006, 45, 7982-7984. [CrossRef]

34. Kim, J.R.; Michielsen, S. Photodynamic activity of nanostructured fabrics grafted with xanthene and thiazine dyes against opportunistic fungi. J. Photochem. Photobiol. B 2015, 150, 50-59. [CrossRef] [PubMed]

35. Kim, J.R.; Michielsen, S. Photodynamic antifungal activities of nanostructured fabrics grafted with rose bengal and phloxine b against Aspergillus fumigatus. J. Appl. Polym. Sci. 2015, 132. [CrossRef]

36. Boury, F.; Ivanova, T.; Panaieotov, I.; Proust, J.; Bois, A.; Richou, J. Dilatational properties of adsorbed poly (D, L-lactide) and bovine serum albumin monolayers at the dichloromethane/water interface. Langmuir 1995, 11, 1636-1644. [CrossRef]

37. Mansur, H.S.; Sadahira, C.M.; Souza, A.N.; Mansur, A.A. FTIR spectroscopy characterization of poly (vinyl alcohol) hydrogel with different hydrolysis degree and chemically crosslinked with glutaraldehyde. Mater. Sci. Eng. C 2008, 28, 539-548. [CrossRef]

38. Du, Y.; George, S.M. Molecular layer deposition of nylon 66 films examined using in situ ftir spectroscopy. J. Phys. Chem. C 2007, 111, 8509-8517. [CrossRef]

39. Kim, J.R.; Michielsen, S. Synthesis of antifungal agents from xanthene and thiazine dyes and analysis of their effects. Nanomaterials 2016, 6, 243. [CrossRef] [PubMed]

40. Kim, J.R.; Sharma, S. Acaricidal activities of clove bud oil and red thyme oil using microencapsulation against HDMs. J. Microencapsul. 2011, 28, 82-91. [CrossRef] [PubMed] 
41. Pasay, C.; Mounsey, K.; Stevenson, G.; Davis, R.; Arlian, L.; Morgan, M.; Vyszenski-Moher, D.; Andrews, K.; McCarthy, J. Acaricidal activity of eugenol based compounds against scabies mites. PLoS ONE 2010, 5, e12079. [CrossRef] [PubMed]

42. Varel, V.H.; Miller, D.L. Eugenol stimulates lactate accumulation yet inhibits volatile fatty acid production and eliminates coliform bacteria in cattle and swine waste. J. Appl. Microbiol. 2004, 97, 1001-1005. [CrossRef] [PubMed]

43. Ignatowicz, S.; Brzostek, G. Use of irradiation as quarantine treatment for agricultural products infested by mites and insects. Int. J. Radiat. Appl. Instrum. C Radiat. Phys. Chem. 1990, 35, 263-267. [CrossRef]

44. Kim, H.K.; Kim, J.R.; Ahn, Y.J. Acaricidal activity of cinnamaldehyde and its congeners against Tyrophagus putrescentiae (acari: Acaridae). J. Stored Prod. Res. 2004, 40, 55-63. [CrossRef]

(C) 2017 by the authors. Licensee MDPI, Basel, Switzerland. This article is an open access article distributed under the terms and conditions of the Creative Commons Attribution (CC BY) license (http:/ / creativecommons.org/licenses/by/4.0/). 